\section{Internal-external control of reinforcement and embedded-figures performance}

\author{
JUNE E. CHANCE and ALVIN G. GOLDSTEIN \\ University of Missouri, Columbia, Missouri 65201
}

\begin{abstract}
Male and female Ss were tested in an extended series of 68 embedded figures. Rate of decrease in discovery time was related to $\mathrm{Ss}^{\circ}$ attitudes about locus of control of reinforcing outcomes. Results confirmed those of an earlier study, showing that practice dissipated sex-related performance differences observable in early trials.
\end{abstract}

The two purposes of this investigation were to determine (1) if between-S differences in generalized expectancy for internal vs external control of reinforcing outcomes were related to differential rates of improvement among Ss in time needed for figure discovery in an embedded figures task and (2) if the results of an earlier experiment concerning the effects of practice on embedded figures performances by Goldstein and Chance (1965) could be replicated with a new group of Ss.

Field dependence and independence as constructs describing a stable and sex-related dimension of perceptual and cognitive functioning are widely accepted in psychology. The embedded figures test (EFT; Witkin, 1950) is also widely accepted as an adequate (and convenient) measure of this disposition. However, Sherman (1967) in a recent review of the literature concerning sex differences in space perception and other aspects of intellectual functioning concludes that EFT performance is largely a function of visual space-perception skill. She notes that sex differences in this skill, favoring males, have been reported repeatedly, even in tasks where no analytic activity or resolution of conflict in the visual field is required. Further, she summarizes a number of studies showing that opportunities to manipulate, perform, and otherwise practice with visual space-perception problems are consistently found to be associated with increases in subject skill. Sherman's review supports a hypothesis that differential practice may be the key to individual differences commonly observed in this skill. She suggests that cultural sex-typing of a host of common activities could easily account for differential opportunity to practice visual space-perception skills for the two sexes. Goldstein and Chance (1965) also had proposed and tested a differential practice hypothesis, specifically with regard to the EFT. They predicted that male-female differences in discovery times observed during early trials would no longer be obtained after an extended series of trials. This prediction was confirmed.
These investigators also found in that earlier study that although all Ss improved in EFT performance with successive trials, rates of improvement differed from $S$ to $S$. This observation would hardly be remarkable in any learning study; however, as Glaser (1967) has noted, despite a voluminous psychological literature regarding human learning, there is a relative scarcity of studies addressed to influences of individual differences (except for those concerning abilities and the construct of anxiety) on the learning process.

Rotter (1954) has proposed a personality theory assigning a concept of expectancy learning a central role in determining behavior change and performance differences. The theory states that performance differences, aside from those describable as ability differences, are a function of the expectancy held by the performer that a given behavior will lead to a given outcome-preferred by $S$ among other available outcomes-in a given situation. Expectancy, stated as a probability of success of a particular behavior, should increase or decrease systematically in relation to the performer's experience. However, data gathered in various experimental situations soon suggested that regular change in expectancy in the direction and extent implied by preceding outcome occurred insofar as $S$ perceived outcome as contingent on his own behavior. If $S$ perceived outcome as controlled by someone or something else, expectancy and subsequent performance of the reinforced behavior were less predictable. In the light of these findings, Rotter (1966) proposed a generalized expectancy for internal vs external control of reinforcement. This generalized expectancy is differentially evoked by various situational cues; in addition, individuals also differ in their generalized predisposition to interpret a variety of situational cues as indicating a high degree of behavior-outcome contingency

Another purpose of this study was to examine whether individual differences in rate of improvement in figure-discovery time were associated with individual S's predisposition to interpret reinforcing events as either internally or externally determined. It was predicted that S's generalized expectancy of more personal control over outcomes of his own behavior would favor more effective learning performance on his part. The EFT provides a learning task for college adults uniquely suited to testing effects of internal-external control expectancy on learning performance.

A variety of investigations of correlates of internal-external expectancy support the possibility that differences in rate of learning could be related to subject attitude, in a situation where S's alertness, activeness, and readiness to evaluate the outcomes of his own efforts can influence his effectiveness. For instance, it has been found that differences in internal-external attitude are associated with S's: alertness to cues present (Phares, 1962); retention of more information pertinent to his immediate goals (Seeman, 1963; Seeman \& Evans, 1962); more active seeking and better utilization of information (Davis \& Phares, 1967; Phares, 1968); forming more independent evaluations of situations (Crowne \& Liverant, 1963); taking more plausible risks in the interest of gain (Liverant \& Scodel, 1960); and his commitment to more active attempts to solve problems (Gore \& Rotter, 1963; Strickland, 1965). In addition, other studies (Chance, 1965; McGhee \& Crandall, 1968), using a measure of internal-external expectancy adapted to school children and focusing specifically on academic achievement behavior, have found relationships with measures of academic achievement performance.

\section{PROCEDURE}

Sixty-eight embedded figures were employed. These same figures are described in Goldstein and Chance (1965). No two complex figures were alike, although the 14 simple figures to be discovered were each repeated several times.

On each trial $S$ was first shown the complex figure for $15 \mathrm{sec}$ and then the simple figure for $10 \mathrm{sec}$. Finally, the complex figure was presented again. S could request to see the simple figure again, but at no time could he view both figures simultaneously. Score was time taken to find the simple figure. Time taken to trace incorrect figures, if any, was excluded from S's score, and $S$ was not permitted to work longer than $2.5 \mathrm{~min}$ on any figu:e.

Data were obtained in two experimental sessions separated by $48 \mathrm{~h} ; 34$ stimuli were presented to $S$ on each occasion. The order of presentation of stimuli was reversed for 
Table 1

Intercorrelations of Measures of Embedded Figures Performance, Internal-External Control Scale Scores, and Intellectual Ability $\dagger$

\begin{tabular}{lccccc}
\hline \multicolumn{1}{c}{ Variables } & 1 & 2 & 3 & 4 & 5 \\
\hline 1. EF percent decrease score & -- & $-.41^{*}$ & +.23 & -.02 & +.01 \\
2. 1-E control score & $-.45^{* *}$ & -- & -.29 & +.11 & +.06 \\
3. Initial EF score & +.08 & +.18 & -- & -.29 & -.35 \\
4. Verbal ability score & -.09 & -.10 & -.14 & -- & +.29 \\
5. Nonverbal ability score & +.05 & -.06 & -.34 & +.29 & -- \\
\hline
\end{tabular}

tCorrelations in women's data are shown above the diagonal; men's below.

${ }^{*} p<.05 ; * *<<.02$

half the Ss of each sex. Ss were 29 college men and 26 college women. At the end of the second session, all Ss were also administered two brief measures of general intellectual ability-one verbal, one nonverbal-taken from the Army Alpha and Beta tests, respectively. Both tests are closely timed and involve recognition of similarities and differences between pairs of stimuli. Ss were also administered the 29-item forced-choice version of the Rotter Internal-External Control Scale (Rotter, 1966).

\section{RESULTS AND DISCUSSION}

All Ss decreased their discovery time for finding hidden figures over 68 trials. When the average performances of men and women were compared, they differed significantly during the first 10 trials and failed to do so during the last 10 trials. Men required an average of $43.9 \mathrm{sec}$ $(S D=22.6)$ to find the simple figure on Trials $1 \cdot 10$, while women required a mean of $58.9 \mathrm{sec}(\mathrm{SD}=32.3)$. This difference is significant $(t=2.02, d f=53, p<.05)$. In contrast, on the last 10 trials men required an average of $14.1 \mathrm{sec}(\mathrm{SD}=11.6)$ and women $18.6 \mathrm{sec} \quad(\mathrm{SD}=13.3)$. This difference is not significant. (In view of the skewed nature of the distributions of scores on the last 10 trials, the same mean comparisons were also performed using the Mann-Whitney U-test. The comparison between means for males and females on Block I trials yielded a $\mathrm{z}$ value of 1.96 with a two-tailed $p$ value just at the .05 level. The mean comparison for the last block of trials yielded an insignificant $z$ value.)

The finding of the earlier study (Goldstein \& Chance, 1965), which was itself suggested by observations derived from Witkin's data (1950), was thus confirmed. It may be concluded that disappearance of sex-related performance differences among college students in EFT performance as a result of a small amount of practice is a regularly appearing phenomenon. The finding lends further support to the view that male/female differences in EFT performance may be in large part a function of differential opportunity to develop the requisite skill. It is also noteworthy that improvements in performance occur rapidly when practice is provided. This observation should suggest some caution about the use of the EFT as a measure from which to make inferences about so pervasive and long-term a personal disposition as field dependency.

When absolute decreases in discovery time were correlated with levels of initial performance, the resulting values of $r$ were +.86 for males and +.92 for females. Therefore, in order to examine relationships between $S$ variables and rate of decrease in discovery time, it was necessary to obtain percent decrease scores. Decrease in S's time (Trials 1-10 minus Trials 59-68) was expressed as a percentage of the time taken by $S$ on the first 10 trials. Correlations utilizing this measure and pertinent to the question of whether Ss with more internal attitudes toward control of reinforcement would perform more effectively than $S$ s with more external attitudes are presented in Table 1. (Note that in Table 1 higher internal-external control scale scores indicate more externality of attitude.)

The relationships reported in Table I indicate that: (1) greater belief in internal control of reinforcing outcomes, as contrasted with belief in external control, was associated with more improvement in performance on $E F$, as measured by percent decrease in discovery time over a prolonged series of trials ( $\mathrm{r}$ was -.45 for males and -.41 for females), and (2) these relationships cannot be accounted for on the basis of differences among $S s$ in intellectual ability or differences in initial EF discovery times.

These findings add still another facet to the network of behaviors of which the internal-external control expectancy appears to be predictive. In this instance, differences among individuals in the rate at which a skill in visual perception is improved with practice are related to differences they report in proclivily to regard outcomes of a wide variety of life situations as within their personal control or not. The study lends further support to the usefulness of the internal-external control construct as a way of describing differences among persons that mediate differential effects of learning experiences.

\section{REFERENCES}

CHANCF, J. E: Internal control of reinforcements and the school learning process. Paper given at the Socicty for Research in Child Development. Minneapolis, 1965.

CROWNE, D. P., \& LIVERANT, S. Conformity under varying conditions of personal commitment. Journal of Abnormal \& Social Psychology, 1963, 66, 547-555.

DAVIS, W. L., \& PHARES, E. I, Internal-external control as a determinant of information-secking in a social influence setting. Journal of Personality, 1967, 35, 547-561.

GLASER, R. Some implications of previous work in learning and individual differences. In R. M. Gagne (Ed.), learning and individual differences. Columbus, Ohio: Charles F. Merrill, 1967. Pp. 1-18.

GOLDSTEIN, A. G., \& CHANCE. J. L: liffects of practice on sex-related differences in performance on embedded figures. Psychonomic Science, 1965, 3, 361-362.

GORE, P. M., \& ROTTER, J. B. A personality correlate of social action. Journal of Personality, 1963, 31, 58-64.

LIVL:RANT, S., \& SCODEL, A. Internal and external control as determinants of decision making under conditions of risk. Psychological Reports, 1960, 7, 59-67.

MCGHIE, P. F.. \& CRANDALL. V. C. Beliets in internal-cxternal control of reinforecments and academic performance. Chitd Development, $1968,39,91-102$.

PHARES, [:. J. Pereeptual threshold decrements as a function of skill and chance expectancies. Journal of Pychology, 1962, 53. 399.407.

PHARE:S, I:. J. Differential utilization of information as a function of internal-external control. Journal of Personality. 1968, 36, 649-662.

ROTTIR, J. B. Social learning and clinical psycholog.' New York: Prentice-Hall. 1954.

ROTTI:R. J. B. Generalized expectancies for internat versus external control of reinforcement. Psychological Munographs, 1966.80(1. Whole No. 609).

SLEMAN, M. Alicnation and social learning in a reformatory. American Journal of Sociology. $1963,69,270-284$

SHI:MAN. M.. \& IVVANS. I. W. Alicnation and lcarning in a hospital setting. American Sociological Review. 1962. 27.772-783.

SHI:RMAN. J. A. Problem ol ex diffirences in space pereeption and aspects of intellectaal functioning. Psychological Review. 1967, 74. 290-299.

STRICKL AND. B. R. The prediction of social action from a dimension of internal-external conirol. Journal of Social Psycholosy. 1965. 66. 353-358.

WITKIN. H. A. Individual differences in casc ol perception of embedded figures. Joumal of Personality. 1950. 19, 1-15. 